\title{
The root-soil system of Norway spruce subjected to turning moment: resistance as a function of rotation
}

\author{
T. Lundström • M. J. Jonsson • M. Kalberer
}

Received: 27 February 2007 / Accepted: 6 August 2007 /Published online: 20 September 2007

(C) Springer Science + Business Media B.V. 2007

\begin{abstract}
The reactions of trees to wind, rockfall, and snow and debris flow depend largely on how strong and deformable their anchorage in the soil is. Here, the resistive turning moment $M$ of the root-soil system as a function of the rotation $\phi$ at the stem base plays the major role. $M(\phi)$ describes the behavior of the root-soil system when subject to rotational moment, with the maximum $M(\phi)$ indicating the anchorage strength $M_{\mathrm{a}}$ of the tree. We assessed $M(\phi)$ of 66 Norway spruce (Picea abies L. Karst) by pulling them over with a winch. These 45- to 170year-old trees grew at sites of low and high elevation, with a diameter at breast height $\mathrm{DBH}=14-69 \mathrm{~cm}$ and a height $H=9-42 \mathrm{~m} . M(\phi)$ displayed a strong nonlinear behavior. $M_{\mathrm{a}}$ was reached at a lower $\phi$ for large trees than for small trees. Thus overhanging tree weight contributed less to $M_{\mathrm{a}}$ for the large trees. Overturning also occurred at a lower $\phi$ for the large
\end{abstract}

Responsible Editor: Peter J. Gregory.

T. Lundström • M. J. Jonsson • M. Kalberer

WSL, Swiss Federal Institute

for Snow and Avalanche Research SLF,

CH-7260 Davos Dorf, Switzerland

T. Lundström $(\bowtie)$

Laboratory of Dendrogeomorphology,

University of Fribourg,

1700 Fribourg, Switzerland

e-mail: t.lundstroem@slf.ch trees. These observations show that the rotational ductility of the root-soil system is higher for small trees. $M_{\mathrm{a}}$ could be described by four monovariate linear regression equations of tree weight, stem weight, stem volume and $\mathrm{DBH}^{2} \cdot H\left(0.80<R^{2}<0.95\right)$, and $\phi$ at $M_{\mathrm{a}}, \phi_{\mathrm{a}}$, by a power law of $\mathrm{DBH}^{2} \cdot H\left(R^{2}=\right.$ $0.85)$. We found significantly higher $M_{\mathrm{a}}$ for the lowelevation spruces than for the high-elevation spruces, which were more shallowly anchored, but no significant difference in $\phi_{\mathrm{a}}$. The 66 curves of $M(\phi)$, normalized $\left(_{\mathrm{n}}\right.$ ) by $M_{\mathrm{a}}$ in $M$-direction and by $\phi_{\mathrm{a}}$ in $\phi$ direction, yielded one characteristic average curve: $\bar{M}_{\mathrm{n}}\left(\phi_{\mathrm{n}}\right)$. Using $\bar{M}_{\mathrm{n}}\left(\phi_{\mathrm{n}}\right)$ and the predictions of $M_{\mathrm{a}}$ and $\phi_{\mathrm{a}}$, it is shown that $M(\phi)$ and the curves associated with $M(\phi)$ can be predicted with a relative standard error $\leq 25 \%$. The parameterization of $M(\phi)$ by tree size and weight is novel and provides useful information for predicting with finite-element computer models how trees will react to natural hazards.

Keywords Allometry - Energy absorption capacity · Protective forest - Mechanical modeling .

Tree structure $\cdot$ Uprooting process

$\begin{array}{ll}\text { Abbreviations } \\ \text { Notation } & \text { Description (Unit) } \\ b, \alpha & \text { Regression coefficients } \\ \text { DBH } & \text { Stem diameter on bark at breast height, i.e. } \\ & 1.3 \mathrm{~m}(\mathrm{~m}) \\ \phi & \text { Rotation at the base of the stem due to } M\left(^{\circ}\right)\end{array}$




\begin{tabular}{|c|c|}
\hline$\phi_{\mathrm{a}}$ & $\phi$ at $M_{\mathrm{a}}\left(^{\circ}\right)$ \\
\hline$\phi_{\mathrm{n}}$ & $\phi$ normalized with $\phi_{\mathrm{a}}$ \\
\hline$\phi_{\mathrm{OT}}$ & $\begin{array}{l}\phi \text { at which the tree overturns due to } M^{\mathrm{g}} \\
\text { only }\left({ }^{\circ}\right)\end{array}$ \\
\hline$H$ & Total tree height $(\mathrm{m})$ \\
\hline HE, LE & High-elevation site, low-elevation site \\
\hline$\kappa$ & $\begin{array}{l}\text { Average stem curvature between the stem } \\
\text { base and the stem section initially at } z_{\mathrm{g} 0} \\
\left(\mathrm{~m}^{-1}\right)\end{array}$ \\
\hline$m$ & Weight $(\mathrm{kg})$ \\
\hline$M$ & $\begin{array}{l}\text { Resistive turning moment of the tree root- } \\
\text { soil system }(\mathrm{Nm})\end{array}$ \\
\hline$M_{\mathrm{a}}$ & $\begin{array}{l}\text { Anchorage strength of the tree, i.e. the } \\
\text { maximum } M(\mathrm{Nm})\end{array}$ \\
\hline$M^{\mathrm{F}}$ & $\begin{array}{l}\text { Contribution of the winching force to } M \text {. } \\
M^{\mathrm{F}}=M-M^{\mathrm{g}}(\mathrm{Nm})\end{array}$ \\
\hline$M^{g}$ & $\begin{array}{l}\text { Contribution of overhanging weight of } \\
\text { stem and crown to } M(\mathrm{Nm})\end{array}$ \\
\hline$M_{\mathrm{n}}$ & $M$ normalized with $M_{\mathrm{a}}$ \\
\hline $\bar{M}_{\mathrm{n}}$ & The average $M_{\mathrm{n}}\left(\phi_{\mathrm{n}}\right)$-curve \\
\hline $\mathrm{n}$ & Normalized value (as subscript) \\
\hline $\mathrm{p}$ & Predicted value (as subscript) \\
\hline$P$ & Statistical $P$-value \\
\hline$R^{2}$ & $R$-squared value of a regression \\
\hline SE & Standard error, or after $\pm($ mean value $\pm \mathrm{SE})$ \\
\hline $\mathrm{SE}_{\mathrm{n}}$ & $\begin{array}{l}\text { Relative standard error=SE divided (nor- } \\
\text { malized) by the estimate itself }(-, \%)\end{array}$ \\
\hline$V$ & Volume $\left(\mathrm{m}^{3}\right)$ \\
\hline$X$ & Explanatory variable \\
\hline$x, y, z$ & $\begin{array}{l}\text { Cartesian coordinates of the tree: origin at } \\
\text { stem base; } x=\text { horizontal stem deflection; } \\
z=\text { height above origin. }(\mathrm{m})\end{array}$ \\
\hline$z_{\mathrm{g} 0}$ & $\begin{array}{l}\text { Height of the tree's centre of gravity. } \\
\text { o refers to the initial tree position (m) }\end{array}$ \\
\hline
\end{tabular}

\section{Introduction}

Trees are subject to forces from one or several types of natural hazards during their lifetime. Wind affects all trees. Trees in mountain areas may in addition be affected by rockfall, and snow and debris flows, and also naturally protect lower areas against them (Brang et al. 2006). Independent of which of these hazards a tree is exposed to, its reaction to the acting force is a combination of stem deflection and rotation of the root-soil system (Coutts 1986; Crook and Ennos 1996). A sufficiently strong force will cause failure to either the stem or the root-soil system. Observations of trees completely or partly uprooted by strong winds indicate that the root-soil system is a weak link in the transport of forces from the crown to the ground (Brassel and Brändli 1999). Investigations of tree destruction in rockfall couloirs and snow avalanche tracks indicate that loads of this kind may also cause the tree to partially or completely overturn (Gerber and Schnyder 1998; SLF 2000). Irrespective of the action, the anchorage of trees, especially that of the often shallow-rooted Norway spruce (Picea abies L. Karst), greatly affects the mechanical stability and protection capacity of trees.

When a root-soil system is subjected to a turning moment, it rotates. It appears that the resistive turning moment of the root-soil system $M$ is a function of the rotational angle, i.e. the stem base inclination $\phi$ (Coutts 1983). $M(\phi)$ thus describes the rotational behavior of the root-soil system. The curve of $M(\phi)$ is indispensable for modeling the reaction of a tree exposed to winds, rockfall, and snow and debris flows, and thus for predicting the protection capacity of trees, and for assessing potential hazards and risks. In addition, $M(\phi)$ helps us to understand the uprooting process of trees (Coutts 1983), and can therefore be used, in comparative studies, to explain the effects of forest management on tree anchorage.

The maximum value of $M(\phi)$ is commonly called the anchorage strength $M_{\mathrm{a}}$. The usual method to assess $M_{\mathrm{a}}$ is through winching (e.g. Fraser 1962; Nicoll et al. 2006; Peltola et al. 2000). This experiment can of course also be used to determine $M(\phi)$. Whether the aim is to estimate $M_{\mathrm{a}}$ or $M(\phi)$, a correct analysis needs to take into account the deflection of the tree during the test, because, among other things, the weight of the leaning tree contributes to $M(\phi)$. When $M_{\mathrm{a}}$ is reached, the contribution of the weight can amount to more than $60 \%$ (Coutts 1986). If the stem base inclines more than at $M_{\mathrm{a}}$, it is evident that this proportion increases. Several methods have been developed to assess deflection (Coutts 1986; Hassinen et al. 1998; Lundström et al. 2007).

Despite the frequent use of winching tests to determine $M_{\mathrm{a}}$, little information on $M(\phi)$ is available with regard to different species, ages and growth conditions. In view of the importance of $M(\phi)$ for 
tree stability, this is surprising. Coutts (1983) studied 34-year-old Sitka spruce (Picea sitchensis (Bong.) Carr.) that were pulled over with recordings of $\phi$ and $M$ made simultaneously. This very thorough study of $M(\phi)$ is the only one we found with the inclination measured at the base of the stem from the natural position of the root-soil system up to when it overturned. Crook and Ennos (1996) studied 16-year-old deep-rooted Larch (Larix europea $\times$ L-japonica) pulled at about $20 \%$ of tree height, where the inclination was also recorded. Although the inclination was not measured at the base of the stem, this study provides valuable insights into how the resistive moment of the rootsoil system develops with increasing inclination of the lower part of the stem, up until when the tree overturns. These two studies show that $M$ increases with increasing $\phi$ up to $M_{\mathrm{a}}$ and then decreases until there is complete failure and the root-soil system overturns. However, they do not provide us with any parameterized, quantitative description of $M(\phi)$, which is required when modeling trees in finiteelement models (FEM).

The aim of the present work was to analyze the uprooting process of Norway spruce, with special attention given to the parameterization of $M(\phi)$, from $\phi=0$ to $\phi$ at tree overturning, using tree and site variables. This involved investigating: (1) the general behavior of the root-soil system, the stem, and $M(\phi)$ during the uprooting in winching tests; and (2) the values and allometric descriptions of $M_{\mathrm{a}}$ and of $\phi_{\mathrm{a}}$, i.e. the stem base inclination at $M_{\mathrm{a}}$. In this paper we show that $M(\phi)$ and the curves associated with it can be well parameterized with aboveground tree parameters and are site dependent.

Table 1 Characteristics of the test trees growing at the high elevation site (HE) and at the low elevation site (LE), with minimum, maximum and mean values: $\mathrm{DBH}=$ stem diameter at

\section{Materials and methods}

Sites, stands and trees

We performed winching tests on 66 mature Norway spruce (Picea abies L. Karst.), growing at three different locations in Switzerland. The first location includes six closely situated stands south of Davos, at about $46^{\circ} 46^{\prime} \mathrm{N}, 9^{\circ} 49^{\prime} \mathrm{W}, 1750 \mathrm{~m}$ a.s.1.. The second and the third locations are situated close to Zurich, at $47^{\circ} 22^{\prime} \mathrm{N}, 8^{\circ} 28^{\prime} \mathrm{W}, 620 \mathrm{~m}$ a.s.l., and $47^{\circ} 14^{\prime} \mathrm{N}, 8^{\circ} 53^{\prime} \mathrm{W}$, $460 \mathrm{~m}$ a.s.1.. The growth conditions at the two latter locations were similar and our analysis revealed no significant differences between them for the anchorage characteristics studied. In the following we therefore refer to the Davos location as the highelevation site (HE) and to the two Zurich locations as the low-elevation site (LE). These sites exhibit representative growth conditions, management strategies, tree sizes and ages (Table 1) for the two regions and elevations.

The HE site has an annual mean temperature of $+1{ }^{\circ} \mathrm{C}$ with large diurnal variations, and an annual mean precipitation of $1100 \mathrm{~mm}$. The wind blows generally in the N-S axis with an annual mean and maximum 10-min wind of 2 and $15 \mathrm{~m} / \mathrm{s}$ (MeteoSwiss 2006). With a slope of about $30^{\circ}$, the site faces $\mathrm{W}$ and N. Soils of the shallow B-horizon $(0.05 \mathrm{~m}<$ soil depth $<0.4 \mathrm{~m}$ ) include dystric Cambisols and Podzols (taxonomy according to FAO 1998) with frequent stones. The site, which is a natural Norway spruce habitat, is also dominated by Norway spruce. The forest had a density of between 500 and 1200 trees per ha before the tests, and had been subjected to little or no forest management for at least a century.

breast height; $H=$ tree height; $S=$ slenderness $=H / \mathrm{DBH}(\mathrm{m} / \mathrm{m})$; $L_{\mathrm{c}}=$ crown length $(\mathrm{m})$; Age $=$ cambial age measured at breast height; and RW=mean annual ring width at breast height

\begin{tabular}{|c|c|c|c|c|c|c|c|}
\hline \multirow[t]{3}{*}{ Site } & \multirow[t]{3}{*}{ No. of test trees } & $\mathrm{DBH}(\mathrm{cm})$ & $H(\mathrm{~m})$ & $S(-)$ & $L_{\mathrm{c}} / H(\%)$ & Age (years) & $\mathrm{RW}(\mathrm{mm})$ \\
\hline & & \multicolumn{6}{|l|}{ Min-max } \\
\hline & & \multicolumn{6}{|l|}{ Mean } \\
\hline \multirow[t]{2}{*}{$\mathrm{HE}$} & 21 & $14-49$ & $9.3-29$ & $59-106$ & $35-95$ & $42-271$ & $0.7-2.0$ \\
\hline & & 25 & 21 & 86 & 70 & 90 & 1.3 \\
\hline \multirow[t]{2}{*}{ LE } & 45 & $19-69$ & $16-42$ & $57-119$ & $15-80$ & $41-152$ & $1.4-3.7$ \\
\hline & & 44 & 34 & 80 & 50 & 81 & 2.6 \\
\hline
\end{tabular}


The LE site has an annual mean temperature of $+9^{\circ} \mathrm{C}$, precipitation of $1150 \mathrm{~mm}$, and the wind blows generally in the SW-NE axis with an annual mean and maximum 10-min wind of 2 and $22 \mathrm{~m} / \mathrm{s}$ (MeteoSwiss 2006). Its terrain is in general flat. Soils of the Bhorizon $(0.2 \mathrm{~m}<$ soil depth $<1.2 \mathrm{~m})$ comprise dystric Cambisols and Luvisols. The site can be characterized as a natural Common beech (Fagus sylvatica L.) habitat. Due to selective logging, however, Norway spruce dominates the forest, which, prior to the tests, had a density of between 100 and 350 trees per ha.

During the three months prior to the winching tests and during all tests, the amount of rain was normal to slightly less than normal, the daily mean temperature was above $0^{\circ} \mathrm{C}$ and the wind conditions were calm (MeteoSwiss 2006 and personal site observations).

Winching tests and investigations

All 66 winching tests were carried out similarly to those described in several previous studies of anchorage strength (e.g. Cucchi et al. 2004; Gardiner 1989; Peltola et al. 2000; Stokes et al. 2005). A cable attached to the stem was pulled by a winch until the tree fell, with simultaneous measurements of force and tree position

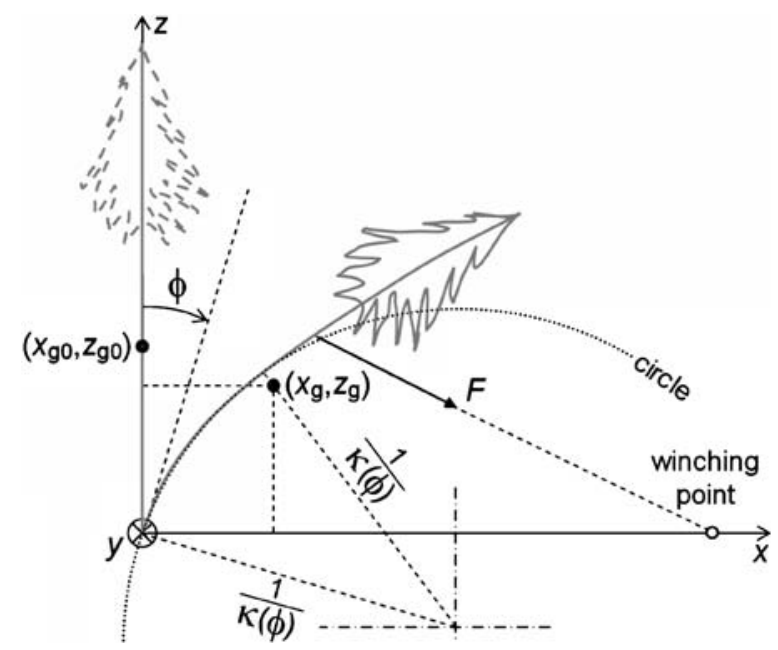

Fig. 1 The winching test. The winching force, $F$, acts in the $x-z$ plane and causes the tree to deflect in the same plane. The stem deflection is a result of the rotation at the stem base $(\phi)$ and the stem curvature. Abbreviations used to calculate the predicted contribution of overhanging tree weight to $M(\phi)$ (cf. end of Mechanical analysis): $\left(x_{\mathrm{g}}, z_{\mathrm{g}}\right)=$ centre of gravity of the tree, initially located at $x=x_{\mathrm{g} 0}=0$ and $z=z_{\mathrm{g} 0} ; \mathrm{\kappa}=$ mean stem curvature between the stem base $(x, z)=(0,0)$ and the stem section initially located at $\left(x_{\mathrm{g} 0}, z_{\mathrm{g} 0}\right)$
(Fig. 1). The winching height was in the range $15-67 \%$ of tree height, but generally $20 \pm 5 \%$ (40 trees, 19 at the LE site and all 21 at the HE site). The trees were winched in the direction of the prevailing winds at the LE site and downslope at the HE site, at a rate of between 1 and $10 \mathrm{~cm} / \mathrm{s}$. The position of the tree during the test was obtained in one of two ways: (1) from a finite-element model of the tree that was provided with measured tree weight and dimensions, and constrained with recorded force and inclination data measured at $2 \%$ relative tree height. Additional inclination data, recorded by inclinometers at $5 \%$ and $20 \%$ relative heights, were used to position the stem of the model by iteratively changing its structural bending modulus of elasticity, which was set constant for the entire stem (see Jonsson et al. (2006) for further detail); (2) from two series of digital images capturing the lower and the upper part of the tree simultaneously as it was winched. The time step of the image series was adapted to capture the tree top deflection at least every $30 \mathrm{~cm}$. The images were then analyzed with the software tool STEMTRACK, which rectifies the images and calculates the deflection of the entire stem in the tree coordinates $(x, y, z)$ for each digital image (the $x$-axis in the horizontal direction of winching and of stem deflection, and the $z$-axis measuring the height above ground). The deflection is parameterized by a high-order polynomial $x(z)$. The precision in $x(z)$ depends on the pixel resolution of the image. We used an image resolution of $768 \times 576$ pixels. If a $30-\mathrm{m}$ high tree is captured entirely in one image, one pixel corresponds to $\sim 10 \mathrm{~cm}$. With a rectification precision of about $4 \mathrm{~cm}$, the rectification accuracy was higher than the pixel resolution. For technical information on STEMTRACK, see http:/www.wsl.ch/forschung/ forschungsunits/lawinen/downloads/Stemtrack.pdf [accessed 6. May 2007]. After each test, the stem diameter and the stem and crown weight were recorded per 1-m sections of height. Among the 45 Norway spruces at the LE site, 37 were investigated previously (Lundström et al. 2007), where the stem weight of each tree was calculated from its on-bark volume and mean bulk density $\left(815 \mathrm{~kg} / \mathrm{m}^{3}\right)$. The annual ring width (RW) was measured with a caliper in stem discs cut close to breast height. The root-soil plate width, depth and height were measured with a meter. On the basis of digital images of the plate, its shape was approximated with an elliptical cross section and depth-dependent 
taper, where single protruding roots and the bent-off part of the plate at the plate hinge are ignored. This parameterization, including results for the LE-site, is reported in detail in Lundström et al. (2007). Details about the test set-ups, measurements, and instruments used are given in Jonsson et al. (2006) and Lundström et al. (2007).

\section{Mechanical analysis}

Given the position of the tree and winching cable during the test and the vertical distribution of weight, the effectively applied rotational moment $M$ at the stem base could be computed as a function of the stem-base inclination $\phi$ (Equation 1)

$M(\phi)=M^{\mathrm{g}}(\phi)+M^{\mathrm{F}}(\phi)$

where $M^{\mathrm{g}}(\phi)$ is the stem base moment due to the overhanging weight $\left({ }^{\mathrm{g}}\right)$ of the stem and crown and $M^{\mathrm{F}}(\phi)$ is due to applied winching force $\left({ }^{\mathrm{F}}\right) \cdot M^{\mathrm{g}}(\phi)$ was calculated as the sum of deflection times weight for 100 equally long stem segments $=H / 100 \cdot M^{\mathrm{F}}(\phi)$ is the vector product of $F(x, z)$ and the coordinates $(x, z)$ for the point where $F$ is applied to the stem, which changes during the test (cf. Fig. 1).

All $M$ :s were calculated between $\phi=0$ (the tree in its natural unloaded state) and $\phi=\phi_{\mathrm{OT}}$, when the tree began to fall (overturn) due to its own overhanging weight only. Beyond $\phi_{\mathrm{OT}}$, the tree is not in equilibrium and our static analysis does not apply.

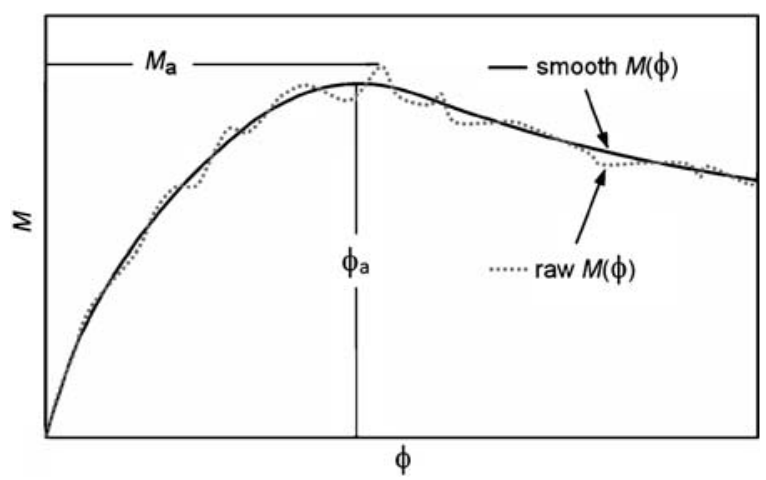

Fig. 2 Schematic description of how parameters were determined from the recorded resistive moment $M$ of the root-soil system as a function of rotation $\phi$ at the stem base. The maximum $M$ of the raw data (raw $M[\phi]$ ) corresponds to the anchorage strength $M_{\mathrm{a}}$ and $\phi_{\mathrm{a}}$ corresponds to the $\phi$ at the maximum $M$ of the smoothed data (smooth $M[\phi]$ )
Knowing $M(\phi)$, the energy absorbed by the root-soil system in rotation $W(\phi)$ could be calculated, as it is represented by the area under the $M(\phi)$-curve (cf. Fig. 2). We determined $W_{\text {tot }}$ ( $W$ absorbed up to $\phi_{\mathrm{OT}}$ ), the anchorage strength $M_{\mathrm{a}}$ (the maximum $M$ $(\phi)$-value), and $\phi_{\mathrm{a}}$. Here, $\phi_{\mathrm{a}}$ refers to the general maximum of the $M(\phi)$-data, which was obtained in three steps, by: (1) estimating $\phi_{\mathrm{a}}$ from a plot of the raw $M(\phi)$-data; (2) smoothing the raw $M(\phi)$-data, applying a $\phi$-smoothing span of $25 \%$ of the estimated $\phi_{\mathrm{a}}$ and using a locally weighted, quadratic, polynomial smooth algorithm (loess, Matlab 7.0, MathWorks, Inc., USA); and (3) determining $\phi_{\mathrm{a}}$ from the maximum of the smoothed $M(\phi)$-data. The purpose with this smoothening was to bring out the general and thus most significant curve maxima (Fig. 2).

The $M(\phi)$-curve described by the raw data was then normalized $(\mathrm{n})$ for each tree by $M_{\mathrm{a}}$ in the $M$-direction and by $\phi_{\mathrm{a}}$ in the $\phi$-direction, yielding $M_{\mathrm{n}}=M / M_{\mathrm{a}}$ and $\phi_{\mathrm{n}}=\phi / \phi_{\mathrm{a}}$. The $M_{\mathrm{n}}\left(\phi_{\mathrm{n}}\right)$-data of the trees at the two sites were then averaged, and then once again for all trees, to yield the average curve $\bar{M}_{\mathrm{n}}\left(\phi_{\mathrm{n}}\right)$ for the HE site, the LE site, and for all trees together. In this averaging, the normalization of $\phi$ resulted in a denser $\phi$-graduation for trees with higher $\phi_{\mathrm{a}}$-values. To avoid the $M_{\mathrm{n}}\left(\phi_{\mathrm{n}}\right)$-data of these trees being more strongly statistically weighted than trees with low $\phi_{\mathrm{a}}$-values at the beginning of the $\bar{M}_{\mathrm{n}}\left(\phi_{\mathrm{n}}\right)$-curve, all $M_{\mathrm{n}}\left(\phi_{\mathrm{n}}\right)$ data sets were subjected to interpolation with a $\phi_{\mathrm{n}}$-step of 0.01 prior to averaging, using a piecewise cubic polynomial algorithm (pchip, Matlab).

Finally, curves of predicted ( $\mathrm{p}) M(\phi), M^{\mathrm{g}}(\phi), M^{\mathrm{F}}(\phi)$, and $W(\phi)$ were calculated. Here, the $M\left(\phi_{\mathrm{p}}\right)_{\mathrm{p}}$ was obtained by reversing the normalization described above, i.e. $M_{\mathrm{p}}=M_{\mathrm{a}}(X) \cdot \bar{M}_{\mathrm{n}}$ and $\phi_{\mathrm{p}}=\phi_{\mathrm{n}} \cdot \phi_{\mathrm{a}}(X)$, where $X$ indicates an explanatory variable. To simplify notations from here and on, we use $M(\phi)_{\mathrm{p}}$ for $M\left(\phi_{\mathrm{p}}\right)_{\mathrm{p}}$ and similarly for the related predicted curves. The computation of $M^{\mathrm{g}}(\phi)_{\mathrm{p}}$ as a function of basic dendrometric variables is more complex. Actually, $M^{\mathrm{g}}(\phi)$ depends on how the tree weight is distributed along height $z$ and on the stem curvature that occurs when the tree is winched. Stem curvature, in turn, is influenced by the winching height and angle, as demonstrated in Lundström et al. (2007). With this in mind, we computed $M^{\mathrm{g}}(\phi)_{\mathrm{p}}$ from $\bar{M}_{\mathrm{n}}\left(\phi_{\mathrm{n}}\right)$ and as a function of 
DBH and $H$, taking into consideration the following (cf. Fig. 1): (1) the weight of the straight and unforced tree concentrated in its centre of gravity, at stem height $z_{\mathrm{g} 0}$; (2) a tree height $H$ predicted by $\mathrm{DBH}$, which is to simplify comparisons between trees of different DBH in this paper; the real $H$ should normally be used; (3) only one relative winching height $=0.2 \cdot H$ (the most common in our investigations); (4) an average stem curvature $\kappa$ between the stem base and the point on the stem initially at the height $z_{\mathrm{g} 0}$, calculated as a function of $\phi$; and (5) an inwards radial $\operatorname{shift}=(1-\sin (\beta) / \beta) / \kappa$ $(\phi)$ of the position of the centre of gravity $\left(x_{\mathrm{g}}, z_{\mathrm{g}}\right)$ due to the stem curvature during winching, where $\beta=$ $z_{\mathrm{g} 0} \kappa(\phi)$. As a consequence, $\left(x_{\mathrm{g}}, z_{\mathrm{g}}\right)$ is not situated on the centre line of the stem, but shifted to the winching side during the test. The approximations used in (4) and (5) were based on the observed stem deflections. The calculation of $M^{\mathrm{g}}(\phi)_{\mathrm{p}}$ was then simply the horizontal component of the centre of gravity $x_{\mathrm{g}}$ multiplied by the total weight of the tree. $M^{\mathrm{g}}(\phi)_{\mathrm{p}}$ was also used to calculate $M^{\mathrm{F}}(\phi)_{\mathrm{p}}=M(\phi)_{\mathrm{p}}-M^{\mathrm{g}}(\phi)_{\mathrm{p}}$, and the $\phi$ at which the tree is expected to overturn $\phi_{\mathrm{OTp}}$, i.e. when $M^{\mathrm{F}}(\phi)_{\mathrm{p}}=0$. The curves of $W(\phi)_{\mathrm{p}}$ were obtained by integrating $M(\phi)_{\mathrm{p}}$ with respect to $\phi_{\mathrm{p}}$.

\section{Statistical analysis}

The statistical, allometric relationships between the targeted response variables, i.e. $M_{\mathrm{a}}, \phi_{\mathrm{a}}, W_{\text {tot }}$, and the curve $M_{\mathrm{n}}\left(\phi_{\mathrm{n}}\right)$, and all the aboveground tree parameters (explanatory variables $X$ ) were explored for the HE site, the LE site, and for both sites. This analysis included errors, step-wise multiple regressions and tests for significant differences between the two sites (by adding one fictive term to the two groups, with a value 0 or 1 , in the step-wise regressions). The same analysis procedure was used to check how $z_{\mathrm{g} 0}, \kappa(\phi)$, tree and stem weight, and $H$ could be described by the $X$ 's. Due to strong correlations between the $X$ 's, the step-wise multiple regressions mostly yielded regressions of only one significant $X$. We therefore concentrated on monovariate regressions, including potential combinations and transformations of the $X^{\prime}$ s. The regression equations of $M_{\mathrm{a}}$ were all forced through the origin as $M_{\mathrm{a}}$ is equal to zero if a tree has no weight or has zero dimensions. To evaluate how exact the predicted curves $M(\phi)_{\mathrm{p}}, M^{\mathrm{g}}(\phi)_{\mathrm{p}}$,
$M^{\mathrm{F}}(\phi)_{\mathrm{p}}$, and $W(\phi)_{\mathrm{p}}$ were, we compared the predicted and observed values along these curves, and calculated: (1) the relative errors (error/predicted value) within the range $0<\phi<\phi_{\mathrm{OTp}}$, for the four curves and all trees; (2) the corresponding relative standard error $\mathrm{SE}_{\mathrm{n}}$ for each curve; and finally, (3) the average $\mathrm{SE}_{\mathrm{n}}$, for each of the four curves at the LE site and at the HE site. The SE's were approximately normally distributed for all variables analyzed. The software package S-Plus 2000 (Insightful Corporation, Seattle) was used for all statistical analyses.

\section{Results}

General behavior of the root-soil system, the stem, and the $M(\phi)$ during uprooting

During the winching test and the uprooting of the trees, we observed some characteristic patterns of ground deformation, of stem deflection, and of how the resistive stem-base moment $M$ developed with the stem-base inclination $\phi$. These patterns depended on the site and tree size.

As the tree was winched, the ground on the winching side of the tree sank, whereas that on the other side rose. The ground movements were especially large where lateral roots emerged from the stem. These movements, perpendicular to the pulling direction, are shown in profile in Fig. 3. The maximum deflection, on the winching as well as on the opposite side, approached the centre of the stem as $\phi$ increased. On the winching side it was first discerned at a distance of 2 to $3 \cdot \mathrm{DBH}$ from the stem centre, and reached 1 to $2 \cdot \mathrm{DBH}$ when overturning as the roots and the root-soil plate became very bent at this distance (the "hinge" of the root-soil plate). On the opposite side of the tree, the roots were stretched and failed under traction one after the other. As the tree fell, the lateral roots bent even more on the winching side and the soil failed completely at the hinge. After the test, when the tree was lying down, the root-soil plate was consequently bent-off (i.e. truncated) on the winching side. The root-soil plate of the Norway spruce with shallower roots at the HE site appeared to truncate less than at the LE site, at about 1/2 (HE) 


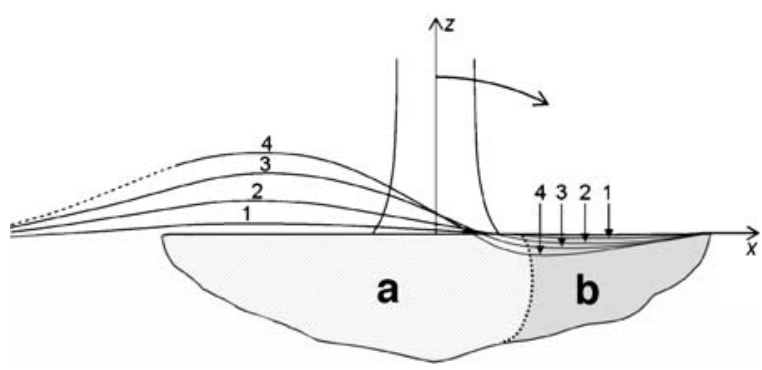

Fig. 3 Example of typical movements of the root-soil plate during uprooting, reconstructed from digital images in the $x-z$ plane. The continuous lines $1-4$ correspond to the profile of the deformed upper surface of the plate, and the dotted line to that of a few roots emerging radially. This Norway spruce grew at the $\mathrm{LE}$ site $(\mathrm{DBH}=39 \mathrm{~cm}$ and $H=32 \mathrm{~m})$, and started to fall due to the overhanging stem and crown weight just after the deformation reached profile 3 . The stem base inclined at $5^{\circ}$, $12^{\circ}, 23^{\circ}$, and $30^{\circ}$ at the profiles $1-4$. The numbers $1-4$ correspond to the positions of maximum deflection on the winching side (shown with arrows) and the opposite side. The profile of the overturned root-soil plate (a) is lighter in color than the profile that remained broken off in the ground (b)

and $2 / 3$ (LE) of the root-soil plate radius in the pulling axis $(x)$. Coarse lateral roots emerging in the pulling direction lowered the inward radial shift of the maximum ground deflection and the subsequent truncation of the root-soil plate. The shape of the root-soil plate was governed much more by the coarse lateral roots at the HE site than at the LE site and was therefore less symmetric and elliptic in plane. The height (stem centre - top of the plate) and width (the lateral radius) were similar at the HE and the LE site, but the depth (below the stem base) was larger $(P<0.001)$ for the trees at the LE site (Table 2). These dimensions, and the deformations of the root-soil plate during and after the uprooting process, varied by up to $50 \%$ and seemed to be mostly governed by the root architecture.
The deflection of the stem and tree originated from the rotation of the root-soil system and the curvature of the stem. Most of the deflection was generally due to the rotation of the root-soil system (cf. Fig. 4a), independent of tree size and site. An inverse relation was observed at large $\phi$ for a few smaller trees (cf. Fig. 4b), especially when winched high up the stem. Generally, small trees deflected more than large trees.

The root-soil system of small trees maintained their resistance to rotation at higher $\phi$-values than larger trees (Fig. 4c,d). As a result, large trees overturned due to the overhanging tree weight at a lower $\phi_{\mathrm{OT}}$ than smaller trees. The minimum $\phi_{\mathrm{OT}}=12^{\circ}$ was recorded for a Norway spruce with a $\mathrm{DBH}=$ $67 \mathrm{~cm}$ at the LE site, and the maximum $\phi_{\mathrm{OT}}=46^{\circ}$ for a Norway spruce with a $\mathrm{DBH}=17 \mathrm{~cm}$ at the $\mathrm{HE}$ site.

Anchorage strength, $M_{\mathrm{a}}$

The $M_{\mathrm{a}}$ was strongly correlated with the weight and size of the tree. Four monovariate descriptions of $M_{\mathrm{a}}$ were obtained, which were of almost equal quality (Table 3). For all of them, $M_{\mathrm{a}} / X$ was lower $(P<0.001)$ at the HE site than at the LE site. Figure 5 exemplifies this for $M_{\mathrm{a}}$ as a function of $m_{\text {stem }}$ and of $\mathrm{DBH}^{2} \cdot H$.

The relative contribution of overhanging tree weight to $M_{\mathrm{a}}, M^{\mathrm{g}}\left(\phi_{\mathrm{a}}\right) / M_{\mathrm{a}}$, was generally between 10 and $25 \%$ for the trees winched at $z=0.2 \cdot H$, but this percentage increased greatly for trees with a $\mathrm{DBH}<30 \mathrm{~cm}$. For example, it was $68 \%$ for the tree in Fig. $4 \mathrm{~b}$ and $d$, which is the highest value obtained. The lowest value of $6 \%$ was observed for a tree of $\mathrm{DBH}=64 \mathrm{~cm}$, which is similar to the $7 \%$ obtained for the tree in Fig. $4 \mathrm{a}$ and c. For all trees winched at $0.2 \cdot H$, the relation $M^{\mathrm{g}}\left(\phi_{\mathrm{a}}\right) /$ $M_{\mathrm{a}}$ at the LE site could be described by $0.374 \cdot\left(\mathrm{DBH}^{2} \cdot H\right)^{-0.552}\left(R^{2}=0.78\right)$ and at the HE site

Table 2 The response variables $(Y)$ root-soil plate width, height, and depth described by the diameter at breast height in simple linear regression, for the trees at the high-elevation (HE) and the low-elevation (LE) site

\begin{tabular}{|c|c|c|c|c|c|c|c|c|}
\hline \multirow[b]{2}{*}{$Y$} & \multicolumn{4}{|l|}{ LE } & \multicolumn{4}{|l|}{$\mathrm{HE}$} \\
\hline & $b$ & $\mathrm{SE}(b)$ & $\operatorname{SE}_{\mathrm{n}}(Y)$ & $R^{2}$ & $b$ & $\mathrm{SE}(b)$ & $\operatorname{SE}_{\mathrm{n}}(Y)$ & $R^{2}$ \\
\hline Width & 3.0 & 0.13 & 0.26 & 0.22 & 3.2 & 0.30 & 0.45 & 0.27 \\
\hline Height & 3.3 & 0.15 & 0.30 & 0.16 & 3.7 & 0.31 & 0.40 & 0.30 \\
\hline Depth & 2.1 & 0.10 & 0.35 & 0.13 & 1.1 & 0.11 & 0.47 & 0.24 \\
\hline
\end{tabular}

All regression coefficients $b$ are significant at $P<0.001$. The width, height, and depth are described in the text and Fig. 3 . 

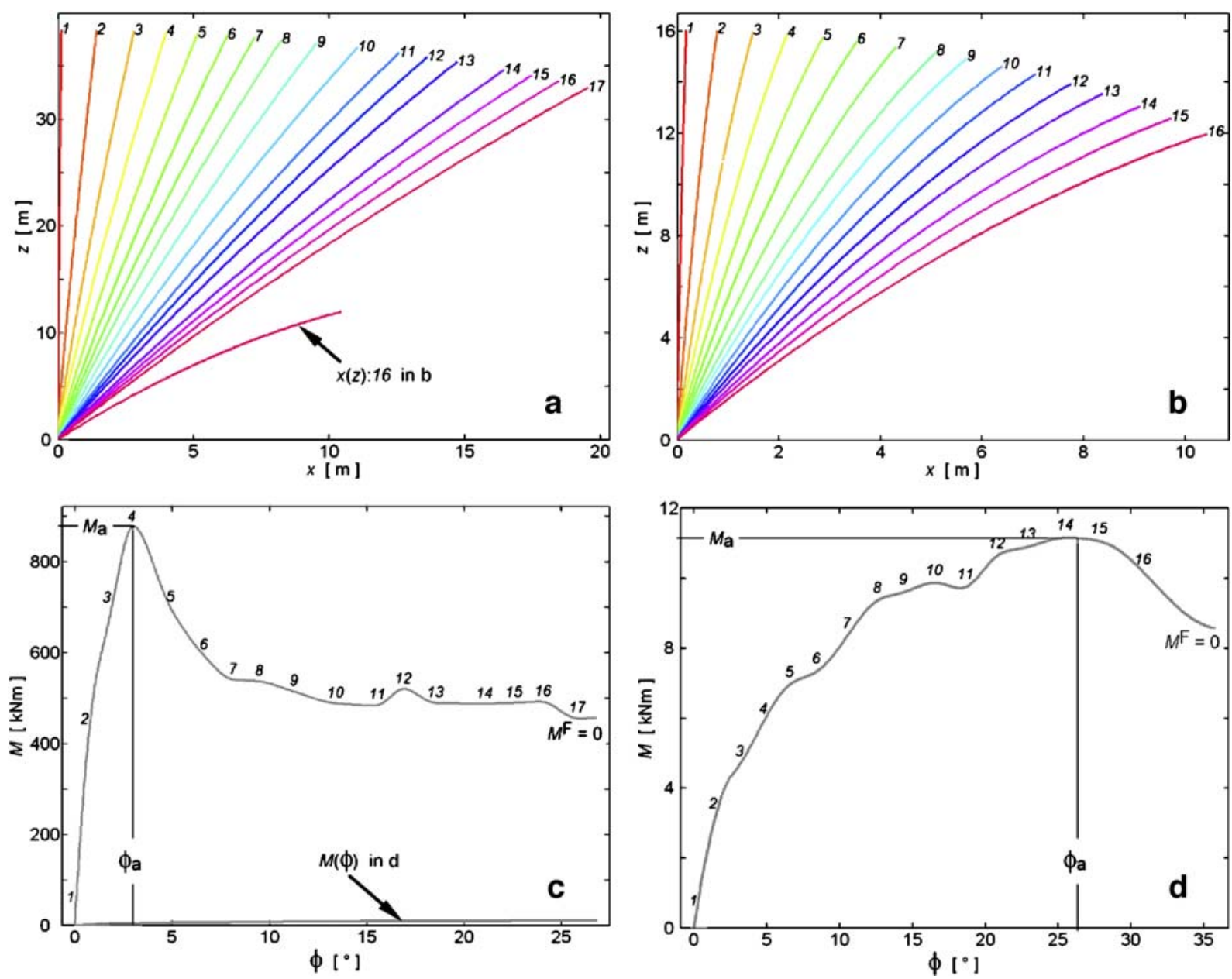

Fig. 4 Stem deflection $x$ according to tree height $z$, compared to the resistive moment of the root-soil system $M$ until the tree fell, here exemplified by two Norway spruce trees: the largest one (a and $\mathbf{c} ; \mathrm{DBH}=69 \mathrm{~cm}, H=39 \mathrm{~m}$, LE site) and one of the smallest (b and d; $\mathrm{DBH}=16 \mathrm{~cm}, H=16 \mathrm{~m}, \mathrm{HE}$ site). The numbers $1-17$

(a and $\mathbf{c}$ ) and 1-16 (b and d) refer to the position of the tree stem during the winching test. Both trees were winched at $0.2 \cdot H . M^{\mathrm{F}}$ is the stem-base moment resulting from the applied winching force $F$. Note that the scales are different in $\mathbf{a}$ and $\mathbf{b}$. To ease scale comparison, $\mathbf{a}$ and $\mathbf{c}$ each include one curve from $\mathbf{b}$ and $\mathbf{d}$

by $0.409 \cdot\left(\mathrm{DBH}^{2} \cdot H\right)^{-0.413}\left(R^{2}=0.81\right)$. As only a few trees were winched at heights other than $0.2 \cdot H$, the effect of winching height on $M^{\mathrm{g}}\left(\phi_{\mathrm{a}}\right) / M_{\mathrm{a}}$ could not be efficiently analyzed statistically. However, it appeared, as expected, that $M^{\mathrm{g}}\left(\phi_{\mathrm{a}}\right) / M_{\mathrm{a}}$ tended to increase with winching height.

Stem-base inclination, $\phi$

The $\phi$ at $M_{\mathrm{a}}$ is described by the regression model (Eq. 2):

$\phi_{\mathrm{a}}=b \cdot\left(\mathrm{DBH}^{2} \cdot H\right)^{\alpha}$

where $b=11.9 \pm 1.0\left[{ }^{\circ} / \mathrm{m}^{3 \alpha}\right]$ and $\alpha=-0.530 \pm 0.027[-$ ]

The quality $\left(R^{2}=0.85, \operatorname{SE}_{\mathrm{n}}\left(\phi_{\mathrm{a}}\right)=0.18\right)$ of this model changed little and did not improve if $\mathrm{DBH}^{2} \cdot H$ was replaced with $V_{\text {stem }}, m_{\text {stem }}$, or $m_{\text {tree}}$, unlike the models describing $M_{\mathrm{a}}$. As no significant difference in $\phi_{\mathrm{a}}$ was found between the LE and HE sites $(P=0.26)$, the final analysis of $\phi_{\mathrm{a}}$ was made with all the data from both sites taken together (cf. Fig. 6).

In contrast, $\phi$ at overturning for the trees winched at $0.2 \cdot H$ was lower $(P<0.05)$ at the HE than at the LE site. At the $\mathrm{HE}$ it could be described by $\phi_{\mathrm{OT}}=$ $33 \cdot\left(\mathrm{DBH}^{2} \cdot H\right)^{-0.15}\left(R^{2}=0.72\right)$, and at the LE site by $\phi_{\mathrm{OT}}=33 \cdot\left(\mathrm{DBH}^{2} \cdot H\right)^{-0.26}\left(R^{2}=0.76\right)$, where the exponent was smaller $(P<0.05)$ for the HE site. 
Table 3 Statistical data related to the models describing the anchorage strength $M_{\mathrm{a}}=b \cdot X[\mathrm{kNm}]$ (maximum stem-base moment), including 45 Norway spruces from the low-elevation site (LE) and 21 from the high-elevation site (HE)

\begin{tabular}{llllll}
\hline$X$ & Site & $b$ & $\mathrm{SE}(b)$ & $\mathrm{SE}_{\mathrm{n}}\left(M_{\mathrm{a}}\right)$ & $R^{2}$ \\
\hline$m_{\text {tree }}$ & $\mathrm{LE}$ & $1.29 \mathrm{E}-01$ & $2.4 \mathrm{E}-03$ & 0.14 & 0.94 \\
& $\mathrm{HE}$ & $7.63 \mathrm{E}-02$ & $2.7 \mathrm{E}-03$ & 0.15 & 0.93 \\
$m_{\text {stem }}$ & $\mathrm{LE}$ & $1.57 \mathrm{E}-01$ & $3.2 \mathrm{E}-03$ & 0.17 & 0.93 \\
& $\mathrm{HE}$ & $9.11 \mathrm{E}-02$ & $3.6 \mathrm{E}-03$ & 0.15 & 0.92 \\
$V_{\text {stem }}$ & $\mathrm{LE}$ & $1.30 \mathrm{E}+02$ & $2.7 \mathrm{E}+00$ & 0.16 & 0.93 \\
& $\mathrm{HE}$ & $7.46 \mathrm{E}+01$ & $3.0 \mathrm{E}+00$ & 0.17 & 0.92 \\
$\mathrm{DBH}^{2} \cdot H$ & $\mathrm{LE}$ & $4.37 \mathrm{E}+01$ & $1.1 \mathrm{E}+00$ & 0.18 & 0.90 \\
& $\mathrm{HE}$ & $2.63 \mathrm{E}+01$ & $1.6 \mathrm{E}+00$ & 0.23 & 0.80 \\
\hline
\end{tabular}

The regressions models are listed top-down according to their quality $\left(R^{2}\right)$ and all $b$ 's are significant $(P<0.001)$.

$m=$ weight $(\mathrm{kg}), V=$ volume $\left(\mathrm{m}^{3}\right), \mathrm{DBH}=$ stem diameter at breast height $(\mathrm{m}), H=$ tree height $(\mathrm{m}), \mathrm{SE}=$ standard error of mean, and $\mathrm{SE}_{\mathrm{n}}=$ relative standard error of mean

\section{Energy absorption}

The total energy absorption by the root-soil system in rotation $W_{\text {tot }}$ was lower $(P<0.001)$ at the HE than at the LE site, as a consequence of the lower $M_{\mathrm{a}}$. At the LE site, it could be described by $W_{\text {tot }}=20.4 \cdot\left(\mathrm{DBH}^{2} \cdot H\right)^{0.79}$ $\left(R^{2}=0.77, \mathrm{SE}_{\mathrm{n}}=0.26\right)$ and $W_{\mathrm{tot}}=367 \cdot \mathrm{DBH}-65.2\left(R^{2}=\right.$ 0.72). At the HE site, the corresponding descriptions were $W_{\text {tot }}=7.47 \cdot\left(\mathrm{DBH}^{2} \cdot H\right)^{0.88}\left(R^{2}=0.78, \quad \mathrm{SE}_{\mathrm{n}}=0.29\right)$ and $W_{\text {tot }}=164 \cdot \mathrm{DBH}-30.1\left(R^{2}=0.72\right)$. The regressions $W_{\text {tot }}(\mathrm{DBH})$ were computed so that they could be compared with the results from previous studies (see Discussion). The relatively large variations in $W_{\text {tot }}$ resulted from variations in $\phi_{\mathrm{OT}}$ and in $M_{\mathrm{a}}$.

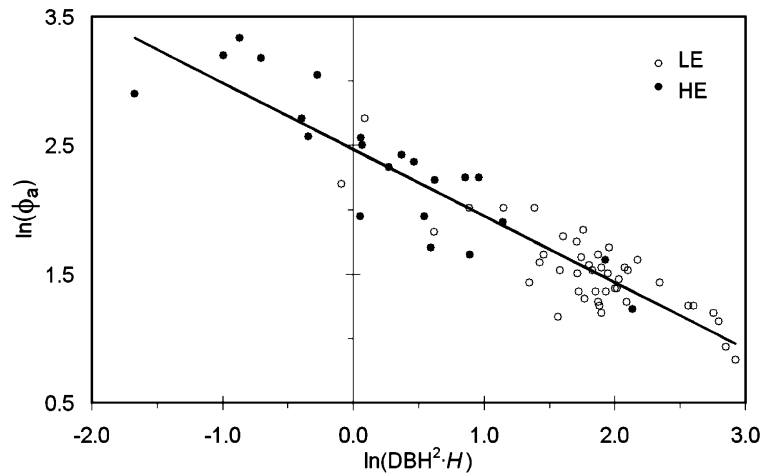

Fig. 6 Stem base inclination $\phi$ at $M_{\mathrm{a}}$, as a function of tree size, at the HE site, the LE site, and a regression (Eq. 2) for all trees (continuous line). DBH is the diameter at breast height and $H$ the tree height

\section{Normalized $M(\phi)$}

The mean curve of the $66 M$ - and $\phi$-normalized $M(\phi)$-curves, $\bar{M}_{\mathrm{n}}\left(\phi_{\mathrm{n}}\right)$, can be seen (Fig. 7) to markedly increase up to $\phi_{\mathrm{a}}$. Then, after a gradual decrease, it almost stabilizes at $\phi_{\mathrm{n}} \approx 5$. The relative standard error in $\bar{M}_{\mathrm{n}}\left(\phi_{\mathrm{n}}\right)$ was on average $\mathrm{SE}_{\mathrm{n}}=4.8 \%$ for $\phi_{\mathrm{n}}<1$ and $\mathrm{SE}_{\mathrm{n}}=8.1 \%$ for $\phi_{\mathrm{n}}>1$. The curves of $\mathrm{SE}_{\mathrm{n}}$ in Fig. 7 (raw data filtered with a $\phi_{\mathrm{n}}$-range $=0.25$ ), display a general increase from $\phi_{\mathrm{n}}=1(0 \%)$ to $\phi_{\mathrm{n}}=$ $8(14 \%)$. The maximum relative error in $\bar{M}_{\mathrm{n}}\left(\phi_{\mathrm{n}}\right)$ belongs to the same tree and was $16 \%$ before $\phi_{\mathrm{n}}=1$ and $21 \%$ after $\phi_{\mathrm{n}}=1$. It was the result of a mobilization and then a sudden release of the traction forces in the roots on the opposite side of the winching cable, which consequently yielded local maxima and minima in $M(\phi)$. Within the $\phi_{\mathrm{n}}$-range with sufficient $M_{\mathrm{n}}\left(\phi_{\mathrm{n}}\right)$-values available for both the

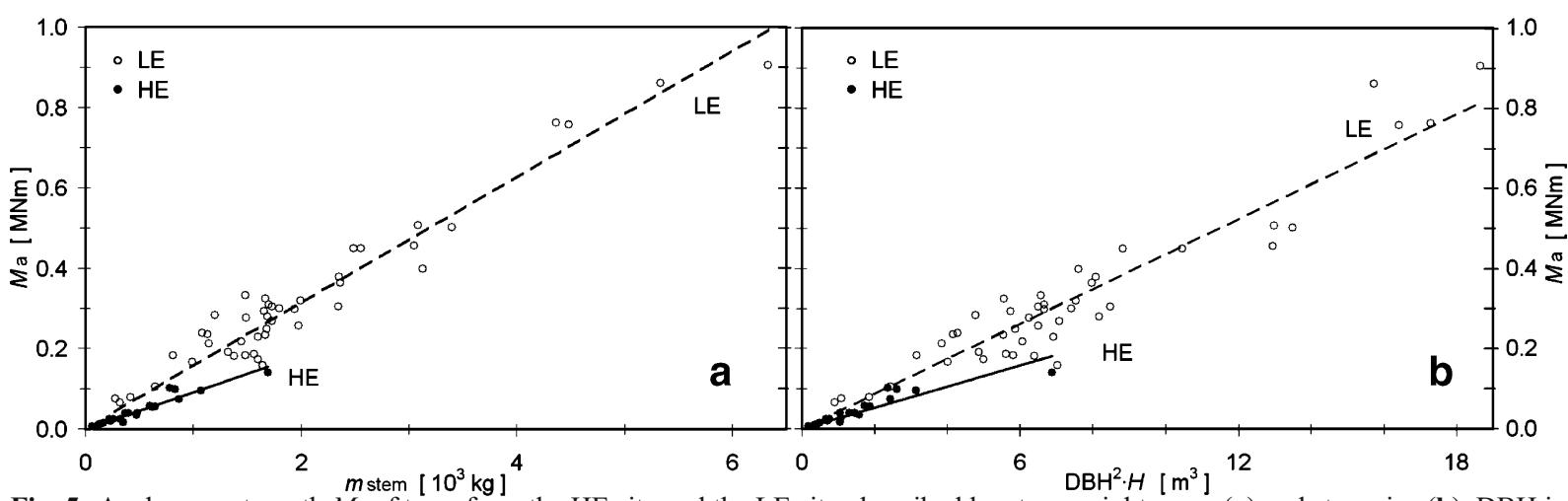

Fig. 5 Anchorage strength $M_{\mathrm{a}}$ of trees from the HE site and the LE site, described by stem weight $m_{\text {stem }}(\mathbf{a})$ and stem size (b). DBH is the diameter at breast height and $H$ the tree height. Characteristics of the four regressions are given in Table 3 


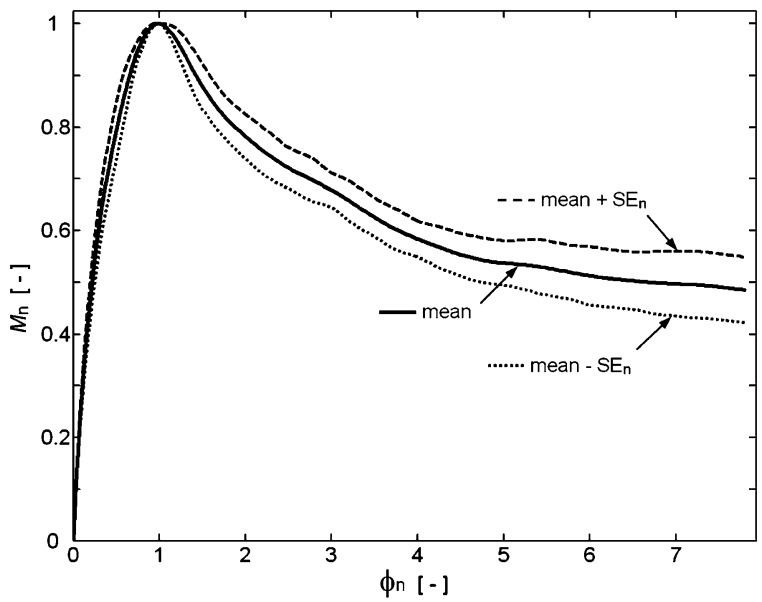

Fig. 7 The $\bar{M}_{\mathrm{n}}\left(\phi_{\mathrm{n}}\right)$-curve (continuous line), including the upper (hatch line) and lower (dotted line) limit of the relative standard error $\operatorname{SE}_{\mathrm{n}}\left(\phi_{\mathrm{n}}\right) . \bar{M}_{\mathrm{n}}\left(\phi_{\mathrm{n}}\right)$ is the mean of all the 66 recorded resistive turning moments at the stem base $M$, normalized (n) with $M_{\mathrm{a}}$, as a function of the rotation $\phi$ at the base of the stem normalized by $\phi_{\mathrm{a}}$

HE and the LE site $\left(0<\phi_{\mathrm{n}}<4.7\right)$, the differences in $\bar{M}_{\mathrm{n}}\left(\phi_{\mathrm{n}}\right)$ were very small and insignificant between the sites. For $\phi_{\mathrm{n}}>5.2, \bar{M}_{\mathrm{n}}\left(\phi_{\mathrm{n}}\right)$ is based on the $M_{\mathrm{n}}\left(\phi_{\mathrm{n}}\right)$ values from the LE site only.

\section{Predictions of $M(\phi)$ and related curves}

The curves of predicted ( $\mathrm{p}$ ) $M, M^{\mathrm{g}}, M^{\mathrm{F}}$, and $W$ as a function of the rotation $\phi$ at the stem base are presented in Fig. 8 for the LE site. The only information used to produce the curves is $\bar{M}_{\mathrm{n}}\left(\phi_{\mathrm{n}}\right)$ (Fig. 7) and $\mathrm{DBH}$, with $M_{\mathrm{a}}\left(\mathrm{DBH}^{2} \cdot H\right)$ (Table 3), $\phi_{\mathrm{a}}$ (Equation 2), and $H(\mathrm{DBH})$. The curves for the HE site have similar shapes (not displayed), apart from three points: (1) their amplitudes are lower, as $M_{\mathrm{a}}$ and to certain extent $M^{\mathrm{g}}$ are lower (the lower $M^{\mathrm{g}}$ result from the lower centre of gravity); (2) $M^{\mathrm{F}}$ turns zero at a slightly higher $\phi$ as a result of the relatively low $M^{\text {g }}$; and (3) the DBH-span is more restricted $(14<\mathrm{DBH}<$ $49 \mathrm{~cm})$ at the HE than at the LE site $(19<\mathrm{DBH}<$ $69 \mathrm{~cm}$, extrapolated to $15<\mathrm{DBH}<70 \mathrm{~cm}$ in Fig. 8).

Concerning the allometric relationships required to compute $M^{\mathrm{g}}(\phi)_{\mathrm{p}}$, and thus $M^{\mathrm{F}}(\phi)_{\mathrm{p}}=M(\phi)_{\mathrm{p}}-M^{\mathrm{g}}(\phi)_{\mathrm{p}}$, the mean curvature between the stem base and the centre of gravity was described by $\kappa=0.58 \cdot \phi / \mathrm{DBH}(\phi$ in ${ }^{\circ}$, DBH in $\left.\mathrm{m}, R^{2}=0.88\right)$ and the tree height by $H=$ $60.5 \cdot \mathrm{DBH}^{0.722}\left(R^{2}=0.83\right)$. Both these expressions include all trees, as no significant differences were found between the sites, even if differences were observed DBH-range-wise. The centre of gravity relative to tree height, on the other hand, differed $(P<0.001)$ between the sites, with $z_{\mathrm{g} 0} / H=$ $0.86 \cdot\left(\mathrm{DBH} \cdot H^{2}\right)^{-0.12}\left(R^{2}=0.32\right)$ at the LE site, and $z_{\mathrm{g} 0} / H=0.46 \cdot\left(\mathrm{DBH} \cdot H^{2}\right)^{-0.048}\left(R^{2}=0.38\right)$ at the $\mathrm{HE}$ site. The total weight of the tree described by $\mathrm{DBH}^{2} \cdot H$ did not vary according to the site. Thus, for all trees included $m_{\text {tree }}=338 \cdot \mathrm{DBH}^{2} \cdot H\left(R^{2}=0.95\right)$.

A comparison of Figs. $8 \mathrm{a}$ and $\mathrm{b}$ shows that $M^{\mathrm{g}} / M$ increases with decreasing tree size, and logically, also with increasing $\phi$. Further, Fig. 8c demonstrates that, if a Norway spruce with a $\mathrm{DBH}=70 \mathrm{~cm}$ exceeds a $\phi=$ $21^{\circ}$, no applied force is required to overturn its rootsoil system; the moment due to the overhanging tree weight $M^{\mathrm{g}}$ suffices. Finally, Fig. $8 \mathrm{~d}$ shows that the root-soil system in rotation is also an effective energy absorber even beyond $\phi_{\mathrm{a}}$. When the measured DBH and the $H$ of the trees winched at $0.2 \cdot H$ were applied to the allometric relationships required for the predicted curves in Fig. 8a-d, we obtained the following average $\mathrm{SE}_{\mathrm{n}}$ for the HE and the LE sites, respectively: $M(\phi)_{\mathrm{p}}$, $25 \%$ and $21 \% ; M^{\mathrm{g}}(\phi)_{\mathrm{p}}, 21 \%$ and $22 \% ; M^{\mathrm{F}}(\phi)_{\mathrm{p}}, 24 \%$ and $20 \%$; and $W(\phi)_{\mathrm{p}}, 23 \%$ and $19 \%$.

\section{Discussion}

General behavior of the root-soil system, the stem, and the $M(\phi)$ during uprooting

The inward radial shift in maximum deflection of the ground on the winching side of the tree during uprooting indicates that the centre of rotation of the root-soil plate also shifts towards the stem centre. After a relatively small angle of rotation, this centre was situated close to the centre line of the stem. Therefore, the simplification used for calculating the resistive moment of the root-soil system $M(\phi)$, with the centre of rotation at the intersection between the centre line of the stem and the ground, seems justified. To explain the variations in root-soil plate movements during uprooting would require more detailed measurements of root and soil deformations, along the lines of those described in Coutts (1983). The plate movements we observed with Norway spruce are similar to those recorded with Sitka spruce (e.g. Coutts 1983; 

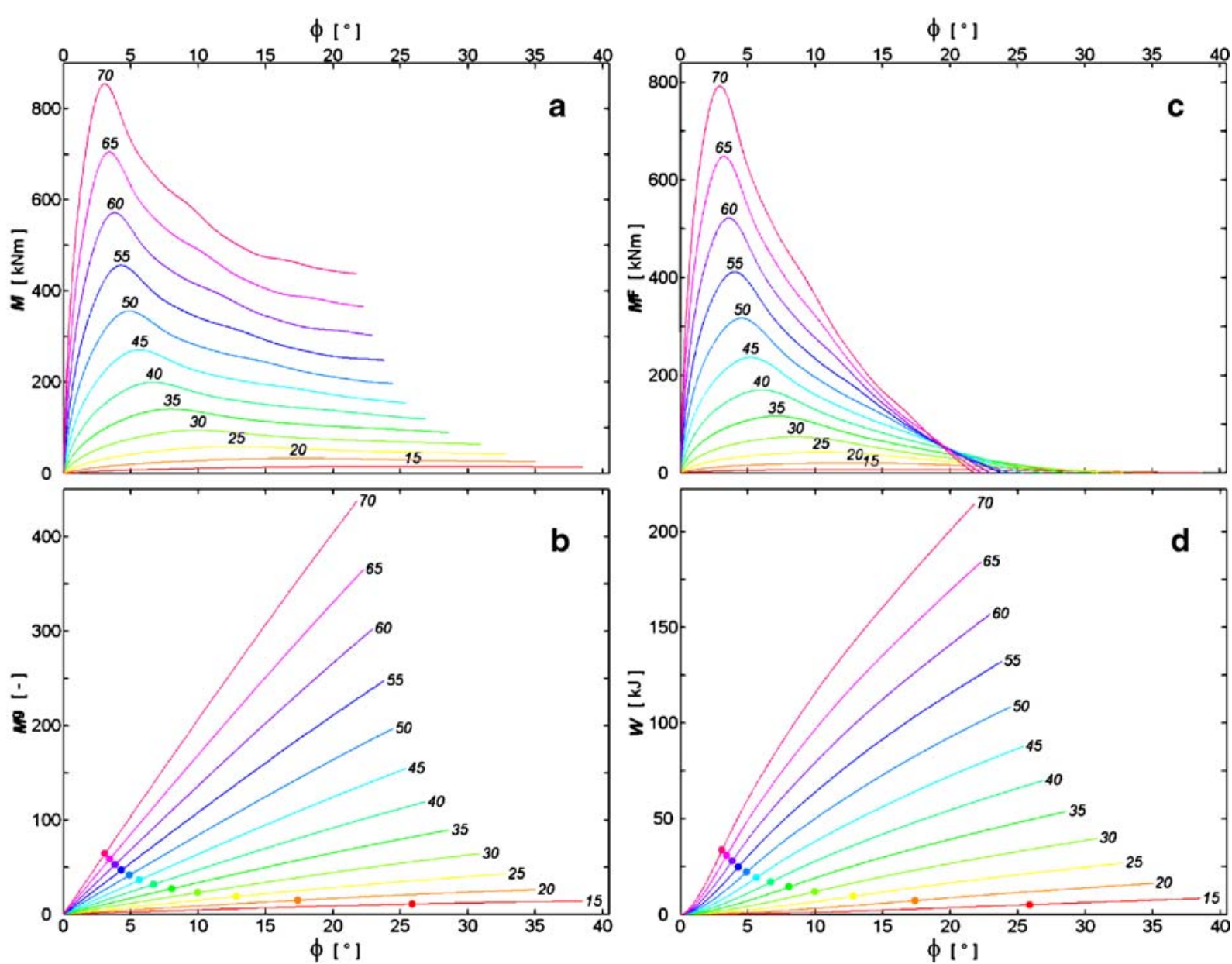

Fig. 8 The resistive turning moment $M$ at the stem base as a function of the rotation $\phi$ at the stem base (a). Stem-base moment due to the overhanging tree weight $M^{\mathrm{g}}$ (b) and to the winching force $M^{F}$ (c), and the energy $W$ absorbed by the root-soil system in rotation (d). All curves display predicted mean values for 12 Norway spruces on the LE site with a $\mathrm{DBH}=15,20, \ldots, 70 \mathrm{~cm}$,

Ray and Nicoll 1998). Thus it is probable that the root-soil failure mechanisms of the Norway spruce we tested resemble those reported for Sitka spruce. The lower truncation of the root-soil plates at the HE site could be due to a concentration of roots in the upper soil layer and thus a higher radial stiffness of the root-soil compound here, but also to a lower total weight of the root-soil plate and of the tree for the Norway spruces at the HE site. The irregular shape of the root-soil plates at the HE site, due to the presence of some coarse roots, resulted in an approximately modeled plate shape (not shown). The latter plates exhibited, however, cross-sectional and a predicted $H$ in the range $16-40 \mathrm{~m}$. The maximum $M(\phi)$, i.e. $M_{\mathrm{a}}$, is indicated by a dot. $M$ and $W$ (a and d) are not dependent on the height of force application, unlike $M^{\mathrm{g}}$ and $M^{\mathrm{F}}$ (b and $\mathbf{c}$ ), which both result from a force application at $0.2 \cdot H$. All curves end at a $\phi$, which corresponds to the predicted overturning of the tree, i.e. the $\phi$-value where $M^{\mathrm{F}}$ turns zero (c)

elliptical shapes and depth-dependent tapers similar to those at the LE site (cf. Lundström et al. 2007), although the HE-plates were only half as deep as the LE-plates (cf. Table 2).

Our analysis of the mechanical behavior of the 66 Norway spruces indicates that it is important to take the non-linearity of $M(\phi)$ into account if the root-soil system exhibits large $M$-values. $M>M_{\mathrm{a}} / 3$, which corresponds to a stem-base inclination of about $\phi=\phi_{\mathrm{a}} / 5$, can in this context be considered large (cf. Figs. 2 and 4). A Norway spruce exceeds this $\phi$ threshold (Vanomsen 2006) during storm-force winds when large amplitude swaying occurs. A model tree 
with a fully clamped stem base would underestimate its capacity to "follow the flow" and thus its resistance to lateral pressure from, e.g., wind and snow.

The characteristic shape of our $M(\phi)$-curves (Fig. 7) is similar to that modeled for maritime pine (Pinus pinaster Ait.) by Fourcaud et al. (2003). It differs, however, from the $M(\phi)$ obtained by Dupuy et al. (2005) for various kinds of root-soil system in that the latter $M(\phi)$ exhibits no positive change in gradient after $\phi_{\mathrm{a}}$. Concerning experimentally assessed $M(\phi)$, Crook and Ennos (1996) recorded $M(\phi)$ for deep-rooted larch, although they refer to $\phi$ as the stem inclination at $0.2 \cdot H$. To compare our results with theirs, we additionally computed $M\left(\phi_{0.2 \mathrm{H}}\right)$ (data not shown). For corresponding tree sizes, we found the curve shapes were similar, but the $M(\phi)$ of our Norway spruce dropped more abruptly after $\phi_{\mathrm{a}}$. These differences indicate that the root-soil systems of the deep-rooted larches resist rotation better after $\phi_{\mathrm{a}}$ than the shallow-rooted Norway spruce we tested.

The $M(\phi)$ of Sitka spruce studied by Coutts (1986) exhibits a two-phase behavior. It is initially relatively stiff and almost ideally elastic. Then, at a small $\phi$, it suddenly becomes very deformable and almost ideally plastic at a quasi-constant $M \approx M_{\mathrm{a}}$ accompanied by fracturing, until overturning. This $M(\phi)$-behavior resembles that described by Dupuy et al. (2005). Coutts (1986) recorded overturning at $\phi$-values comparable to ours, with trees of the same tree size, just after $\phi_{\mathrm{a}}$ was reached.

It appears that two general, characteristic shapes of $M(\phi)$ exist, the first type being described by Crook and Ennos (1996), Fourcaud et al. (2003), and our data, and the second by Coutts (1986) and Dupuy et al. (2005). However, to explain the existence of the two shapes, we do not have enough information about: (i) the analysis method; (ii) the failure mechanisms and the deformation of the root-soil system while $M(\phi)$ is recorded; and (iii) comparable information on the soil and the root systems. It should be kept in mind in future investigations of $M(\phi)$ that (i)-(iii) should be documented.

Anchorage strength, $M_{\mathrm{a}}$

The lower $M_{\mathrm{a}}$ at the HE site is probably a result of the shallower root-system there, due to the site having a shallower B-horizon, a shorter vegetation period, and less available nutrition, than the LE site (Köstler et al.
1968; Soethe et al. 2006). The HE site is also exposed to weaker winds. Trees are known to develop their anchorage in response to wind forces (Lundström et al. 2007; Nicoll and Ray 1996). In addition, the trees at the HE site get less light due to the dense stand and the slope (facing $\mathrm{E}$ and $\mathrm{N}$ ), which may inhibit root growth (Polomski and Kuhn 1998). We did not investigate the root architecture of all the trees tested systematically. However, the depth of the rootsoil plate was twice as large at the LE than at the HE site, which we interpreted as meaning that the root system at the LE site was more developed, based on the relationships between the size of the root-soil plate and the total root mass for Norway spruce grown on similar soil (Bolenikus 2001). Despite their lower $M_{\mathrm{a}}$, the HE spruces could be relatively more stable to wind, as they do not grow to be as tall as those at the LE site and have a lower centre of gravity. The HE and the LE spruces were growing in typical conditions for the region and the elevation. The elevation is, at least in the Alps, related to several growth condition parameters (e.g. soil type, depth, moisture, and temperature, slope, management strategies, and tree age). It is likely that Norway spruce trees growing at the same elevations as those in this study, but under different conditions, will exhibit different anchorage characteristics.

Among the four regression models proposed for $M_{\mathrm{a}}$ (Table 3$), M_{\mathrm{a}}\left(\mathrm{DBH}^{2} \cdot H\right)$ seems to be the most useful, as it requires only two records of tree size, and no pulling over of the tree. In addition, $\mathrm{DBH}^{2} \cdot H$ is frequently referred to in the literature, which enables comparisons of $M_{\mathrm{a}}$. Referring to the comparison with other $M_{\mathrm{a}}$-studies of conifers in Lundström et al. (2007), it appears that the Norway spruces at the LE site exhibit among the highest $M_{\mathrm{a}}$, whereas the $M_{\mathrm{a}}$ at the HE site is close to the average. However, there are only limited possibilities to compare the $M_{\mathrm{a}}$ obtained in this study with existing data, as most previous studies have focused on smaller and younger trees (e.g. Cucchi et al. 2004; Peltola et al. 2000) and mainly on Sitka spruce (e.g. Achim et al. 2003; Fraser and Gardiner 1967; Ray and Nicoll 1998). Moreover, the regression equations of $M_{\mathrm{a}}$ were not always forced through the origin, and $M^{\mathrm{g}}(\phi)$ was not systematically included in $M_{\mathrm{a}}$ in these studies. We found that $M^{\mathrm{g}}\left(\phi_{\mathrm{a}}\right) / M_{\mathrm{a}}$ increases with decreasing tree size by $\left(\mathrm{DBH}^{2} \cdot H\right)^{-0.5}$ and can reach $70 \%$, a value that is also reported in Coutts (1986). When modeling mechanical tree 
stability, it is probably essential to account for all contributions to the applied moment at the stem base when analyzing $M(\phi)$ as well as its maximum, $M_{\mathrm{a}}$. This should also enable comparisons between $M_{\mathrm{a}}$ from experiments with different winching heights or tree characteristics.

\section{Stem-base inclination, $\phi$}

Small trees display greater values of $\phi_{\mathrm{a}}$ (Equation 2) and $\phi_{\mathrm{OT}}$ than larger trees. This means that small trees have a more deformable root-soil system in rotation. Consequently, small trees are less likely to fail when exposed to wind, snow and debris flow, than large ones as their deflection is more efficient, i.e. they tend to follow the flow rather than opposing it. The stem deflections observed during the winching tests of small trees and the analysis of $M^{\mathrm{F}}(\phi)=M(\phi)-M^{\mathrm{g}}(\phi)$ suggest that, if a force is applied high up the stem to a sufficiently small tree, it may be bent down to the ground without overturning (cf. Fig. $8 \mathrm{c}, M_{\mathrm{F}}\left(\phi=40^{\circ}\right.$, $\mathrm{DBH}=15 \mathrm{~cm})>0$ ). It would be worth investigating when this occurs, e.g. for which tree sizes, species, and heights of force application, and relating it to the adaptive growth and survival of trees growing in snow avalanche tracks or on extremely windy spots.

\section{Energy absorption}

The root-soil system appears to be an effective energy absorber when subject to a rotation caused by e.g. impacting rocks or snow flow. Thanks to the ductility of the root-soil system, the energy $W(\phi)$ absorbed in rotation continues far beyond $\phi_{\mathrm{a}}$ and even beyond the limit of tree stability. The major part of the total energy absorption capacity actually occurs after $M_{\mathrm{a}}$ is reached. This finding is similar to Crook and Ennos' observation (1996) that the root-soil system of larch maintains resistance to rotations beyond $70^{\circ}$. This has implications for the protection capacity of trees and forests. The root-soil system of a tree subjected to a dynamic loading may experience large rotations without the influence of overhanging tree weight. The effective total energy absorption of the dynamically loaded root-soil system may therefore be substantially larger than that of the statically loaded one.

The $W(\phi)$-values at overturning $W_{\text {tot }}$ of our Norway spruces can be compared to the values recorded for the Common beech (Stokes et al. 2005), which also include the contribution of overhanging tree weight to $W(\phi)$. Our LE-site Norway spruces display a similar $W_{\text {tot }}=367 \cdot \mathrm{DBH}-65$ to their $W_{\text {tot }}=411 \cdot \mathrm{DBH}-59$, whereas our HE-site spruces had a considerably lower $W_{\text {tot }}=$ 164.DBH-30. The difference in $W_{\text {tot }}$ between the LE and the HE site is due to the different $M_{\mathrm{a}}$, which is governed by growth and soil conditions (e.g. Cucchi et al. 2004; Moore 2000). The growth conditions of the Common beech seem similar to that of the HE-site Norway spruce. This confirms the general opinion in forestry that Common beech has a larger $W_{\text {tot }}$ (and $M_{\mathrm{a}}$ ) than Norway spruce. A scientifically based conclusion would require more systematic data on the growth conditions of the two species. In our study, and also in Stokes et al's (2005), $W_{\text {tot }}$ was investigated statically. If the root-soil system is subject to dynamic loading, it may in addition absorb energy related to inertia.

Predictions of $M(\phi)$ and related curves

The differences between the predicted $(\mathrm{p})$ curves $M(\phi)_{\mathrm{p}}, M^{\mathrm{g}}(\phi)_{\mathrm{p}}, M^{\mathrm{F}}(\phi)_{\mathrm{p}}$, and $W(\phi)_{\mathrm{p}}$ and those actually observed with the 66 trees tested may at first sight appear great. However, this should be seen in the context of the simplifications made and the fact that only three explanatory variables, $\mathrm{DBH}, H$, and site, were used (for the site variable, see the end of the Anchorage strength section).

The calculation of $M^{\mathrm{g}}(\phi)_{\mathrm{p}}$ is geometrically inexact because we assume the tree weight to be concentrated in the tree's centre of gravity. However, we estimated this inexactness to produce less than 5\% relative error, which must be put in relation to the statistical error of $M^{\mathrm{g}}(\phi)_{\mathrm{p}}$ of about $20 \%$. As the computation of $M^{\mathrm{g}}(\phi)_{\mathrm{p}}$ only requires the $\bar{M}_{\mathrm{n}}\left(\phi_{\mathrm{n}}\right)$-curve and the aboveground parameters DBH and $H$, it is a useful and straightforward way of estimating the contribution of tree weight to $M(\phi)$.

The relative standard errors in predicted curves of 19 to $25 \%$ can first be compared to the other relative standard errors obtained in our study, e.g. with the different models of $M_{\mathrm{a}}$ (Table 3). It should also be remembered that the values of $M(\phi)$ and related curves depend on several above- and belowground characteristics of the tree, each exhibiting variations according to the local growth conditions (cf. Blackwell et al. 1990 for belowground related variations in $M$ ). Hence, the errors can be considered low and the curves acceptable for further use. To what extent they can be 
applied to other sites and trees will not be clear until comparative results are available. Our investigations do, however, indicate that knowing the local $M_{\mathrm{a}}$ (the amplitude of the $M(\phi)$-curve) can help to reduce potential errors in $M(\phi)_{\mathrm{p}}$. If we had not used different $M_{\mathrm{a}}$ in predicting $M(\phi)_{\mathrm{p}}$ for the HE and LE sites, which provide quite different growth conditions, the errors in $M(\phi)_{\mathrm{p}}$ would have been several times greater.

\section{Conclusions and outlook}

The behavior of the root-soil system subjected to rotation is decisive for interactions between trees and wind, rockfall, snow avalanches and debris flow. The parameterization of a tree's resistive root-soil moment as a function of its rotation, according to tree size and weight, provides an important basis for predicting such interactions in computer simulations, e.g. for use in assessing hazards and risks. Similar studies with species other than Norway spruce and with different site conditions would be valuable for comparison. Then it should be possible to make better predictions and thus improve scientifically based forest management and optimize ways of providing protection against specific natural hazards.

Acknowledgements We thank the Board of the Swiss Federal Institutes of Technology for funding (Tree stability and natural hazards), all people involved in the tree stability project for field assistance, Pierre Vanomsen for valuable collaboration, and Silvia Dingwall for revision of the text.

\section{References}

Achim A, Nicoll BC, Mochan S, Gardiner BA (2003) Wind stability of trees on slopes. In: Ruck B, Kottmeier C, Mattheck C, Quine C, Wilhelm G (eds) Wind effects on trees. University of Karlsruhe, Karlsruhe, pp 231-237

Blackwell PG, Rennolls K, Coutts MP (1990) A root anchorage model for shallowly rooted Sitka spruce. Forestry 63:73-92

Bolenikus D (2001) Zur Wurzelausbildung von Fichte (Picea abies L. Karst) und Weisstanne (Abies alba Mill.) in gleich - und ungleichaltrigen Beständen. Berichte Freiburger Forstliche Forschung 35:155

Brang P, Schönenberger W, Frehner M, Schwitter R, Thormann J-J, Wasser B (2006) Management of protection forests in the European Alps: an overview. Forest Snow Landsc Res 80:23-44

Brassel P, Brändli U-B (1999) Inventaire forestier national suisse. Haupt, Berne, p 442
Coutts MP (1983) Root architecture and tree stability. Plant Soil 71:171-188

Coutts MP (1986) Components of tree stability in Sitka spruce on peaty gley soil. Forestry 59:173-198

Crook MJ, Ennos AR (1996) The anchorage mechanics of deep rooted larch, Larix europea $x$ L. japonica. J Exp Bot 47:1509-1517

Cucchi V, Meredieu C, Stokes A, Berthier S, Bert D, Najar M, Denis A, Lastennet R (2004) Root anchorage of inner and edge trees in stands of Maritime pine (Pinus pinaster Ait.) growing in different podzolic soil conditions. Trees 18:460-466

Dupuy L, Fourcaud T, Stokes A (2005) A numerical investigation into the influence of soil type and root architecture on tree anchorage. Plant Soil 278:119-134

FAO (1998) Soil map of the world. Revised legend. FAOUNESCO, Food and Agriculture Org. of the United Nations, Rome, p 119

Fourcaud T, Danjon F, Dupuy L (2003) Numerical analysis of the anchorage of maritime pine trees in connection with root structure. In: Ruck B, Kottmeier C, Mattheck C, Quine C, Wilhelm G (eds) Wind effects on trees. University of Karlsruhe, Karlsruhe, pp 323-330

Fraser AI (1962) The soil and roots as factors in tree stability. Forestry 35(2):117-127

Fraser AI, Gardiner JBH (1967) Rooting and stability in Sitka spruce. HMSO, London, p 28

Gardiner BA (1989) Mechanical characteristics of Sitka spruce. Forestry Commission, Edinburgh, p 11

Gerber W, Schnyder D (1998) Attention, chutes de pierres. Des ouvrages de protection plus efficaces. Arguments de la recherche 14:12-17

Hassinen A, Lemettinen M, Peltola H, Kellomaki B, Gardiner B (1998) A prism-based system for monitoring the swaying of trees under wind loading. Agric For Meteorol 90:187-194

Jonsson MJ, Foetzki A, Kalberer M, Lundström T, Ammann W, Stöckli V (2006) Root-soil rotation stiffness of Norway spruce (Picea abies L. Karst) growing on subalpine forested slopes. Plant Soil 285:267-277

Köstler JN, Brückner E, Bibelriether H (1968) Die Wurzeln der Waldbäume. Verlag Paul Parey, Hamburg Berlin, p 284

Lundström T, Jonas T, Stöckli V, Ammann W (2007) Anchorage of mature conifers: resistive turning moment, root-soil plate geometry, and orientation of root growth. Tree Physiol 27:1217-1227

MeteoSwiss (2006) Climate database. Swiss National Weather Service http://www.meteoschweiz.ch/web/en/services/ data_portal.html

Moore JR (2000) Differences in maximum resistive bending moments of Pinus radiata trees grown on a range of soil types. For Ecol Manag 135:63-71

Nicoll BC, Ray D (1996) Adaptive growth of tree root systems in response to wind action and site conditions. Tree Physiol 16:891-898

Nicoll BC, Gardiner BA, Rayner B, Peace AJ (2006) Anchorage of coniferous trees in relation to species, soil type, and rooting depth. Can J For Res 36:1871-1883

Peltola H, Kellomäki S, Hassinen A, Granander M (2000) Mechanical stability of Scots pine, Norway spruce and 
birch: an analysis of tree-pulling experiments in Finland. For Ecol Manag 135:143-153

Polomski J, Kuhn N (1998) Wurzelsysteme. Haupt, Bern Stuttgart Wien, p 290

Ray D, Nicoll BC (1998) The effect of soil water-table depth on root-plate development and stability of Sitka spruce. Forestry 71:169-182

SLF (2000) Der Lawinenwinter 1999: Ereignisanalyse. Eidg. Inst. für Schnee - und Lawinenforsch. (SLF), Davos, p 588

Soethe N, Lehmann J, Engels C (2006) Root morphology and anchorage of six native tree species from a tropical montane forest and an elfin forest in Ecuador. Plant Soil 279:173

Stokes A, Salin F, Kokutse AD, Berthier S, Jeannin H, Mochan S, Dorren L, Kokutse N, Abd Ghani M, Fourcaud T (2005) Mechanical resistance of different tree species to rockfall in the French Alps. Plant Soil 278:107-117

Vanomsen P (2006) Der Einfluss der Durchforstung auf die Verankerung der Fichte hinsichtlich ihrer Sturmresistenz. Monogr. Eidgenössische Technische Hochschule ETH, Zürich, p 248 